\title{
Undifferentiated embryonal sarcoma of the liver in adults: Retrospective analysis of a case series and systematic review
}

\author{
BIN SHU, LEI GONG, XIN HUANG, LIPING CAO, ZHE YAN and SHIZHONG YANG \\ Center of Hepatopancreatobiliary Diseases, Beijing Tsinghua Changgung Hospital, \\ School of Clinical Medicine, Tsinghua University, Beijing 102218, P.R. China
}

Received January 30, 2020; Accepted June 15, 2020

DOI: $10.3892 /$ ol.2020.11963

\begin{abstract}
Adult undifferentiated embryonal sarcoma of the liver (UESL) is an aggressive malignant tumor. As UESL is rare, the literature predominantly includes case reports, with a limited number of small case series. The aim of the present study was to investigate the presentation, treatment modalities and outcomes of this rare tumor. The present study includes a case series of adult UESL and a systematic review. A single-institution case series of adult UESL were retrospectively analyzed, and a systematic review of adult UESL was performed by searching MEDLINE, Web of Science, EMBASE, the Google Scholar database and the Cochrane Library. For all identified adult UESL cases, the demographic variables, treatments and survival were analyzed. Three female adult patients with UESL (median age, 21 years) were successfully treated by complete tumor resection, with or without adjuvant chemotherapy, at Beijing Tsinghua Changgung Hospital between 2015 and 2018. Of these patients, two are currently alive (follow-up, 9 and 41 months), and one died after pulmonary recurrence 17 months post-diagnosis. The present systematic review identified 108 cases of adult UESL. Among all 111 analyzed cases, the median overall and disease-free survival rates were as follows: 1-year, 72 and 67\%; 3-year,
\end{abstract}

Correspondence to: Dr Lei Gong, Center of Hepatopancreatobiliary Diseases, Beijing Tsinghua Changgung Hospital, School of Clinical Medicine, Tsinghua University, 168 Litang Road, Changping, Beijing 102218, P.R. China

E-mail: gonglei1262@126.com

Abbreviations: UESL, undifferentiated embryonal sarcoma of the liver; ALP, alkaline phosphatase; APTT, activated partial thromboplastin time; PT, prothrombin time; AST, aspartate aminotransferase; ALT, alanine aminotransferase; DBIL, direct bilirubin; GGT, $\gamma$-glutamyl transpeptidase; ALB, albumin; RBC, red blood cell; HGB, hemoglobin; HCT, red blood cell specific volume; PIVKA-II, protein induced by vitamin $\mathrm{K}$ absence or antagonist-II; HAIC, hepatic artery infusion chemotherapy; CA, carbohydrate antigen

Key words: adult liver undifferentiated embryonal sarcoma, surgery, chemotherapy, survival
56 and 40\%; and 5-year, 47 and 35\%, respectively. Treatment strategies combining complete tumor resection and chemotherapy promoted improved overall and disease free survival time compared with radical tumor resection alone. The present analysis included one of the largest case series of UESL in adults, and is the first such study to present survival rates. The results of the present study confirmed that survival was improved by treatment strategies combining complete tumor resection and chemotherapy.

\section{Introduction}

Undifferentiated embryonal sarcoma of the liver (UESL) is an aggressive disease that accounts for $<0.2 \%$ of all primary liver tumors (1). UESL was first described as a mesenchymoma by Donovan and Santulli (2) in 1946, and was subsequently termed malignant mesenchymoma by Stout (3) in 1948 before being first recognized as a distinct form of sarcoma by Stocker and Ishak (4) in 1978.

UESL predominantly develops in the childhood, with a peak incidence between 6 and 10 years of age (4); however, it also occasionally occurs in adults (5). UESL usually manifests with nonspecific clinical presentations and preoperative examination results (3-5). The majority of the relevant studies involve pediatric cases and have reported a poor prognosis, even in patients who undergo complete surgical resection of the tumor $(4,5)$. However, patient prognosis has recently been improved using therapeutic strategies combining surgery with chemotherapy, especially with neoadjuvant chemotherapy.

UESL in adults is extremely rare; to the best of our knowledge, the currently available literature includes only 108 reported cases of UESL in adult patients. Due to the low incidence of UESL, especially among adults, the majority of the literature comprises case reports, with a limited number of small case series. Therefore, limited data are available regarding the prognosis of adults patients with UESL, especially in terms of 1-, 3- and 5-year survival rates. The effects of chemotherapy or neoadjuvant chemotherapy on UESL in the adult population also remain unclear. To improve the prognosis of these patients, more cases and treatment experiences should be reported.

The present study aimed to analyze a single-institution retrospective case series of UESL in adults, which was one of the largest reported series to date and included the first report 
of overall survival in this population, as well as to perform a systematic review of the literature to investigate the presentation, treatment modalities and outcomes of this rare tumor.

\section{Materials and methods}

Retrospective analysis. A retrospective review was conducted of three cases of UELS in patients $>15$ years of age treated at the Center of Hepatopancreatobiliary Diseases of Beijing Tsinghua Changgung Hospital between 2015 and 2018. The recorded data included the demographic (age and sex) and clinical characteristics of the patients, including the year of diagnosis, signs and symptoms at presentation, laboratory data, imaging results, tumor extension, type of surgery, tumor size, pathology reports, use of chemotherapy and interventional therapy, presence and location of recurrence, and the duration of overall survival in months. These results are presented as a descriptive analysis of a case series.

Systematic review. A systematic review of the available literature was performed using MEDLINE, Web of Science, Embase, the Google Scholar database and the Cochrane Library to search for all published studies regarding UELS. The PRISMA guidelines were followed (http://www. prisma-statement.org/). The search terms were 'undifferentiated embryonal sarcoma' and 'adult'. The inclusion criteria were as follows: English or Chinese language, human studies, adult patients ( $\geq 15$ years), full-text availability and completeness of clinical data. Studies lacking primary data were excluded, but were examined to identify any relevant citations. Data extraction from relevant studies was performed to search for additional studies. The search was independently performed by two authors, and disagreements regarding study inclusion were resolved through discussion among all authors. The aforementioned clinical parameters from the cases in the included studies were evaluated.

Statistical analysis. Statistical analyses and graphing were performed using GraphPad Prism 7.0 software (GraphPad Software, Inc.). Survival was estimated using the Kaplan-Meier method, and the results were compared using the two-sided $\log$-rank test. $\mathrm{P}<0.05$ was considered to indicate a statistically significant difference.

\section{Results}

\section{Retrospective analysis of a case series}

Demographic and clinical characteristics. As presented in Table I, the three adult patients with UELS were female, with a mean age of 21 years at diagnosis (range, 15-25 years). Symptoms upon admission included fever, chills, nausea, vomiting and weight loss (patient A), and abdominal pain and mass (patients B and C). Laboratory analysis revealed elevated levels of alkaline phosphatase (ALP, patient A), activated partial thromboplastin time/prothrombin time (patients B and $\mathrm{C}$ ), aspartate aminotransferase, alanine aminotransferase, direct bilirubin, ALP and $\gamma$-glutamyl transpeptidase (patient C), as well as decreased albumin, red blood cell count, hemoglobin and red blood cell-specific volume (patient C). Tumor marker levels were normal in patients $\mathrm{A}$ and $\mathrm{C}$, whereas the level of protein induced by vitamin $\mathrm{K}$ absence or antagonist-II (PIVKA-II) was elevated outside of the normal range in patient $\mathrm{C}$. In all patients, ultrasound examination and computed tomography revealed a cystic and solid mass.

Treatment and outcome. Table II summarizes the treatments and outcomes of the three patients. One patient was admitted to the hospital for recurrent UESL. The lesions involved the right lobe in two cases and the left lobe in one case. One patient had undergone biopsy and neoadjuvant chemotherapy (vincristine, cytoxan and cis-platinum) prior to admission. Two patients received preoperative transarterial chemoembolization. Surgical treatment involved right trisectionectomy in two cases, and extended left hemihepatectomy in one case. Two patients received postoperative chemotherapy (dacarbazine plus lobaplatin or doxorubicin, ifosfamide, mesna and dacarbazine). One patient underwent postoperative hepatic artery infusion chemotherapy.

Two patients experienced recurrence, with one in the lung and the other in the lung plus inguinal lymph nodes. Two patients are currently alive after follow-up, one after 9 months of follow-up and the other after 41 months of follow-up. One patient succumbed to pulmonary recurrence at 17 months.

Pathological characteristics. In one case, the tumor size was $<10 \mathrm{~cm}$; in the other two cases, the tumor size was $>20 \mathrm{~cm}$. The tumor in one case exhibited visible capsule infiltration and tumor thrombus (portal vein and hepatic vein). Immunohistochemical results revealed expression of the cytokeratin antibody AE1/AE3, the melanoma antibody HMB45 and DESMIN in one case; vimentin, CD31 and periodic acid-schiff stain (PAS) positive in two cases; and CD34 and smooth muscle actin in all three cases. The rate of Ki-67 expression was $>60 \%$ in all cases. The results are presented in Table III.

\section{Systematic literature review}

Demographic data. The literature search identified 108 reported adult cases of UESL. Of these cases, 75 were reported and summarized by Pachera et al (6) and Chen et al (7) between 1955 and 2011. An additional 33 cases were reported between 2011 and 2019 (Table IV) (8-36). Thus, including the present case series, a total of 111 adult cases of UESL have been reported to date. Among all cases, the median age was 29 years (range, 15-86 years), and the peak incidence was between the ages of 15 and 24 years (Fig. 1). Sex was reported for 107 patients; of these, 44 (41\%) were men and $63(59 \%)$ were women, with a male: Female ratio of 1:1.4 (Table IV).

Treatment and outcome. Complete treatment and survival data were available for 83 patients. Among these patients, the median follow-up was 18 months (range, 2 days to 204 months), and median survival was 48 months (range, 2 days to 204 months). Among all the 83 patients, the 1-,3- and 5-year overall survival rates were 72,56 and $47 \%$, respectively (Fig. 2A), and the 1-, 3 - and 5-year disease-free survival rates were 67,40 and $35 \%$, respectively (Fig. 2B).

Patients who underwent complete tumor resection with adjuvant and/or neoadjuvant chemotherapy exhibited significantly higher survival rates compared with those in patients who underwent surgery alone. For patients treated with 
Table I. Demographic and clinical characteristics of the patients with undifferentiated embryonal sarcoma of the liver in the retrospective case series.

\begin{tabular}{|c|c|c|c|c|c|c|c|}
\hline No. & $\begin{array}{l}\text { Age, } \\
\text { years }\end{array}$ & Sex & Symptoms & $\begin{array}{l}\text { Laboratory } \\
\text { test results }\end{array}$ & $\begin{array}{l}\text { Tumor } \\
\text { markers }\end{array}$ & US findings & CT findings \\
\hline A & 15 & $\mathrm{~F}$ & $\begin{array}{l}\text { Fever, chill, nausea, vomiting, } \\
\text { weight loss }\end{array}$ & $\uparrow A L P$ & Normal & N.A. & Cystic and solid mass \\
\hline B & 24 & $\mathrm{~F}$ & Abdominal pain and mass & $\uparrow \mathrm{PT}, \mathrm{APTT}$ & Normal & $\begin{array}{l}\text { Cystic and } \\
\text { solid mass }\end{array}$ & $\begin{array}{l}\text { Mass with enhancement in } \\
\text { solid parts }\end{array}$ \\
\hline $\mathrm{C}^{\mathrm{a}}$ & 25 & $\mathrm{~F}$ & Abdominal pain and mass & $\begin{array}{l}\uparrow P T, \text { APTT, AST, } \\
\text { ALT, DBIL, ALP, } \\
\text { GGT; } \downarrow \text { ALB, RBC, } \\
\text { HGB, HCT }\end{array}$ & $\uparrow P I V K A-I I$ & N.A. & $\begin{array}{l}\text { Lobulated low enhancement } \\
\text { mass }\end{array}$ \\
\hline
\end{tabular}

${ }^{\text {aPatient }} \mathrm{C}$ was admitted to hospital for recurrent UESL 2 months after initial surgery. ALP, alkaline phosphatase; GGT, $\gamma$-glutamyl transpeptidase; PT, prothrombin time; APTT, activated partial thromboplastin time; AST, aspartate aminotransferase; ALT, alanine aminotransferase; DBIL, direct bilirubin; ALB, albumin; RBC, red blood cell count; HGB, hemoglobin; HCT, hematocrit value; PIVKA-II, protein induced by vitamin $\mathrm{K}$ absence-II; F, female; N.A., not available; US, ultrasound.

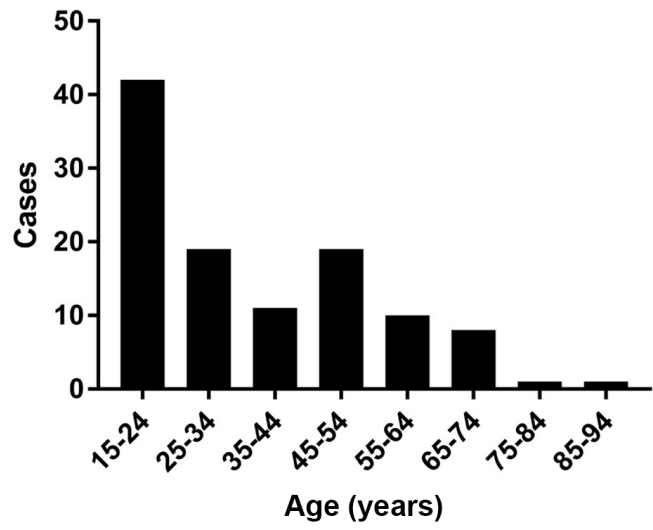

Figure 1. Age distribution of patients with undifferentiated embryonal sarcoma of the liver.

chemotherapy plus surgery vs. surgery alone, the overall survival rates were as follows: 1 -year, $93 \%$ vs. $65 \%$; 3 -year, $80 \%$ vs. $40 \%$; and 5 -year, $63 \%$ vs. $34 \%$ ( $\mathrm{P}=0.0040$; Fig. $3 \mathrm{~A})$. The corresponding disease-free survival rates were as follows: 1 -year, $86 \%$ vs. $47 \%$; 3 -year, $58 \%$ vs. $19 \%$; and 5 -year, $58 \%$ vs. $13 \%$ ( $\mathrm{P}=0.0001$; Fig. 3B).

\section{Discussion}

In the present study, one of largest case series of adult UESL to date was analyzed. The literature review confirmed that a higher survival rate was associated with treatment strategies combining complete tumor resection and chemotherapy compared with radical tumor resection alone. To the best of our knowledge, 111 adult cases of UESL have been reported to date, including the present case series. The present analysis is the first to include a thorough 1-, 3- and 5-year survival rate analysis in this population.

UESL is rare and usually occurs in children; its incidence decreases with increasing age, with peak incidence occurring between the ages of 6 and 10 years $(3,5)$. Among adult patients, the present study identified another peak between the ages of 15 and 24 years. It is possible that UESL is similar to embryonal tumors, and thus may predominantly occur in young adults. In addition, a female preponderance was observed in the present systematic review, with a male: Female ratio of 1:1.4. In the present case series, all three patients were female, and the median age at diagnosis was 21 years (range, 15-25 years).

UESL exhibits a nonspecific clinical presentation. The most common symptoms are right upper quadrant abdominal pain and mass. Other symptoms include vomiting, diarrhea, weight loss, fever, and jaundice $(3,6,7)$. Among the cases included in the present retrospective analysis, the symptoms upon admission were fever, chills, nausea, vomiting and weight loss in one patient, and abdominal pain and mass in the other two patients. Laboratory findings, including liver function and tumor markers, are usually normal at the time of UESL presentation $(6,7)$. Among the present cases, one patient exhibited obviously altered liver function, and tumor markers, including $\alpha$-fetoprotein, carcinoembryonic antigen, carbohydrate antigen (CA)199 and CA125, were negative in all patients. Only one of the three patients exhibited elevated PIVKA-II. In the ultrasound examination and CT scans, UESL often presents as a large solid or cystic mass, with enhancement in the solid parts $(33,37)$. This is similar to the cases in the present study.

From its first recognition as a unique clinicopathologic entity in 1978 until the early 1990s, UESL has been associated with a poor prognosis, even in patients who underwent complete surgical resection of the tumor $(1,2,37)$. Due to its low incidence, especially among adults, UESL survival data are mainly from case reports or small case series of childhood patients. In the initial report by Stocker and Ishak (4), the median survival was $<1$ year, and only $19 \%(6 / 31)$ of the reported patients were alive and disease-free after resection for the median follow-up of 9 months (range, 2-52 months). Among the 40 patients reported in the literature between 1950 and 1988, 47.5\% died after a mean duration of 11.9 months, $15.0 \%$ survived with disease, and $37.5 \%$ were alive and disease-free (average, 37.5 months) (38). 

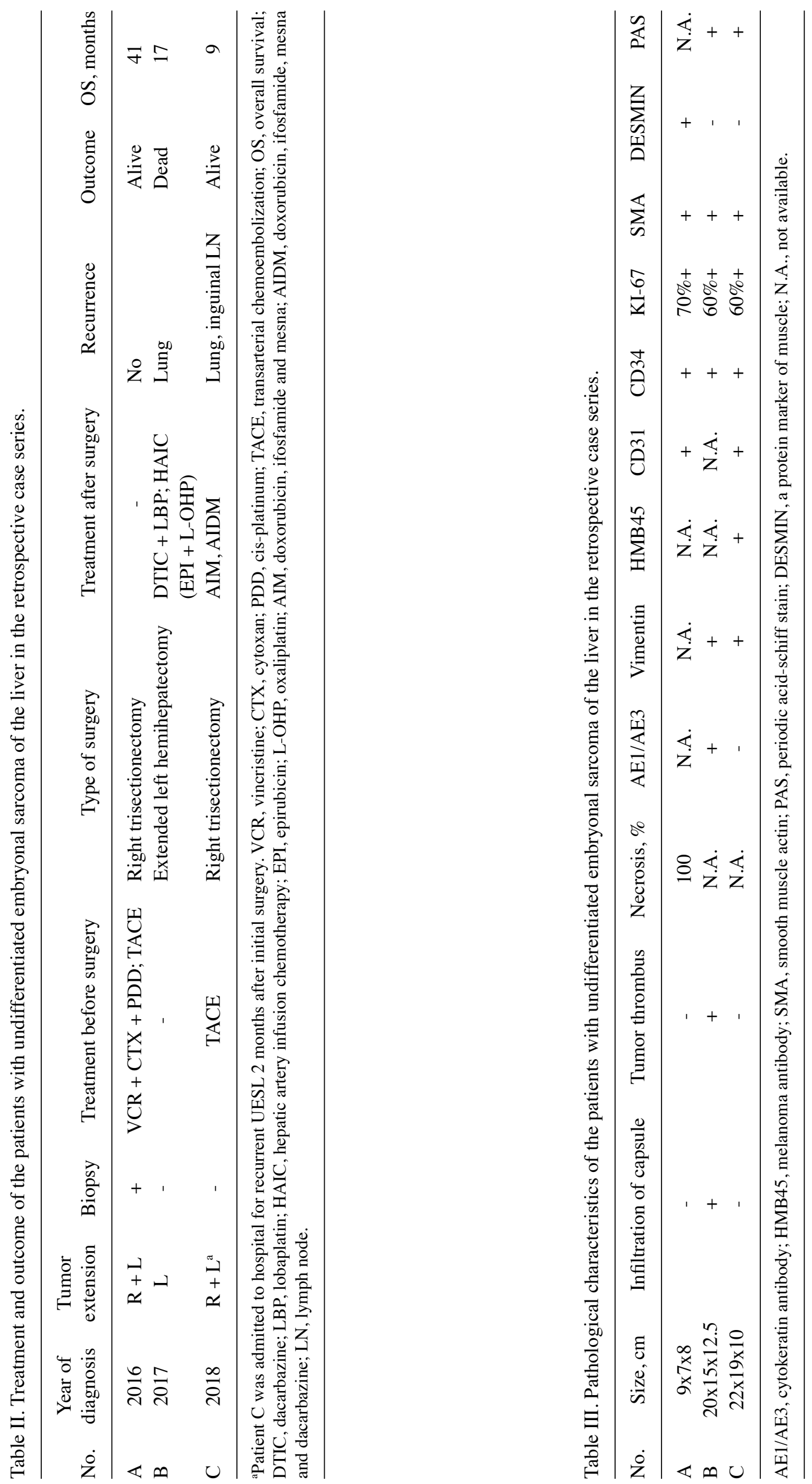


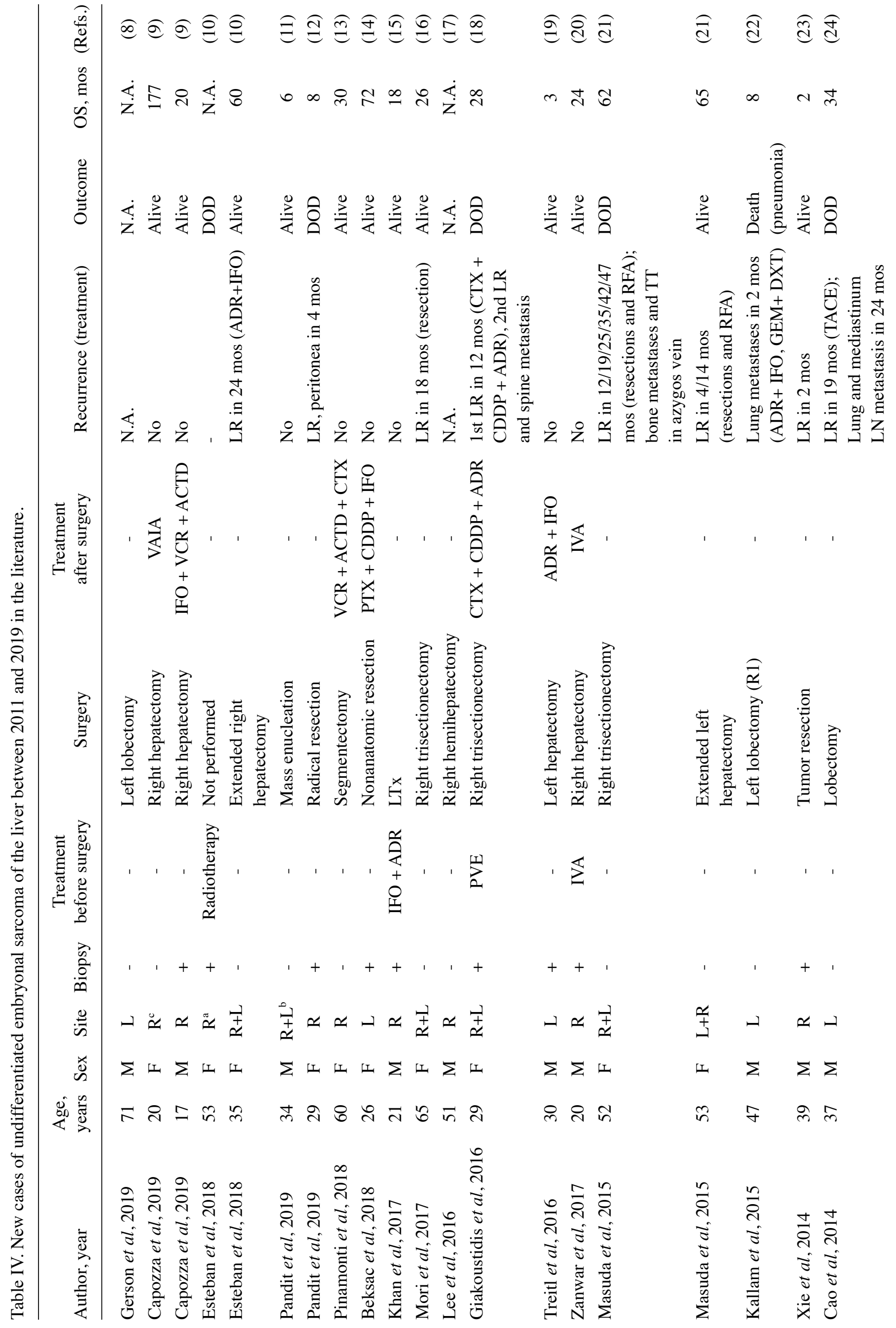




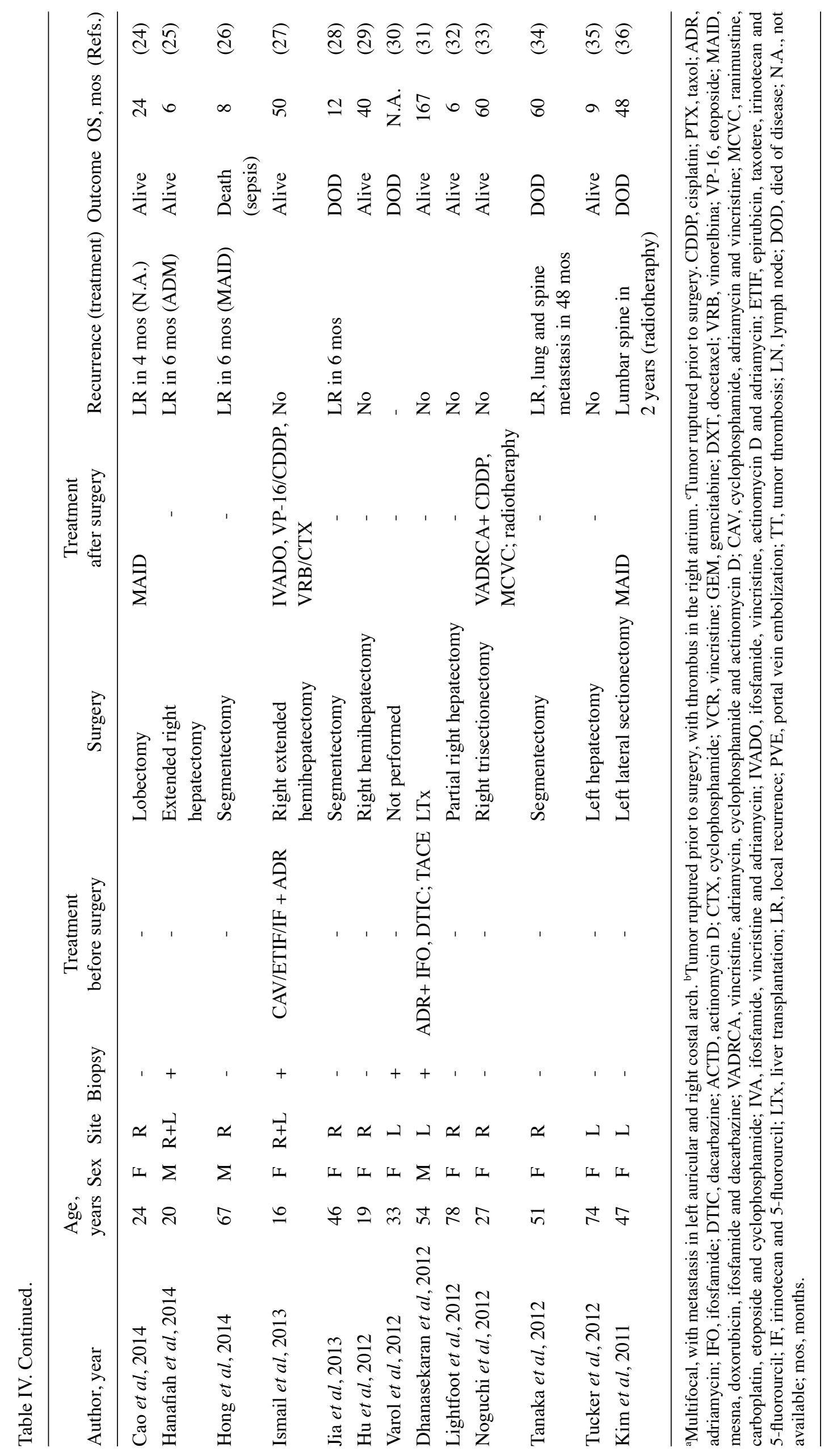



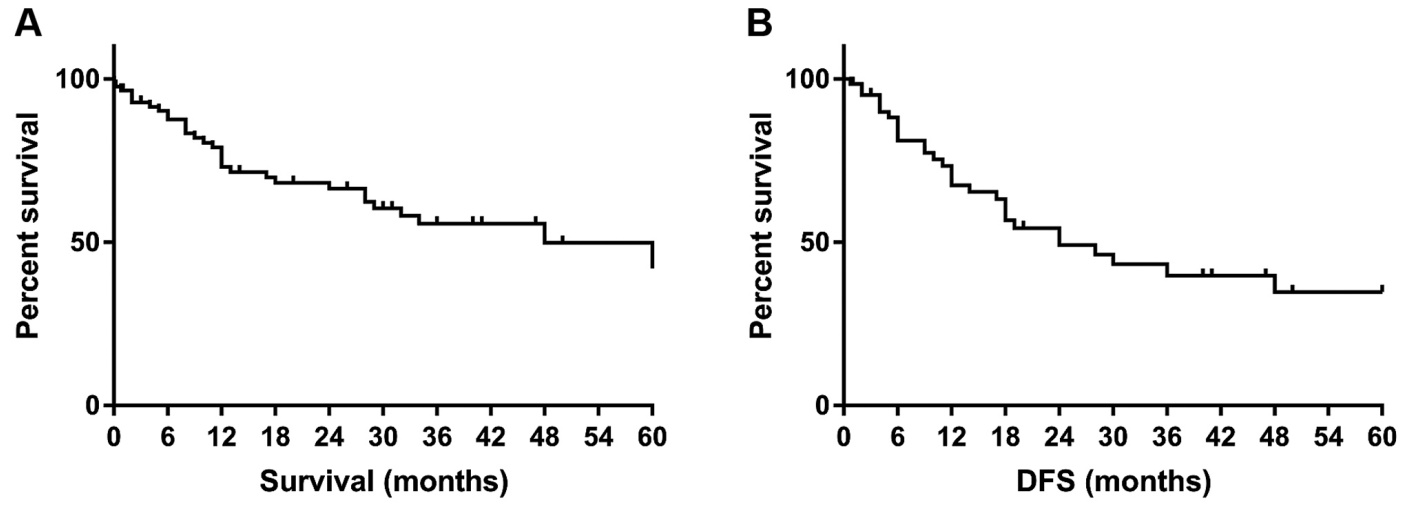

Figure 2. Kaplan-Meyer survival curves of patients with undifferentiated embryonal sarcoma of the liver. (A) Overall survival. (B) DFS. DFS, disease-free survival.
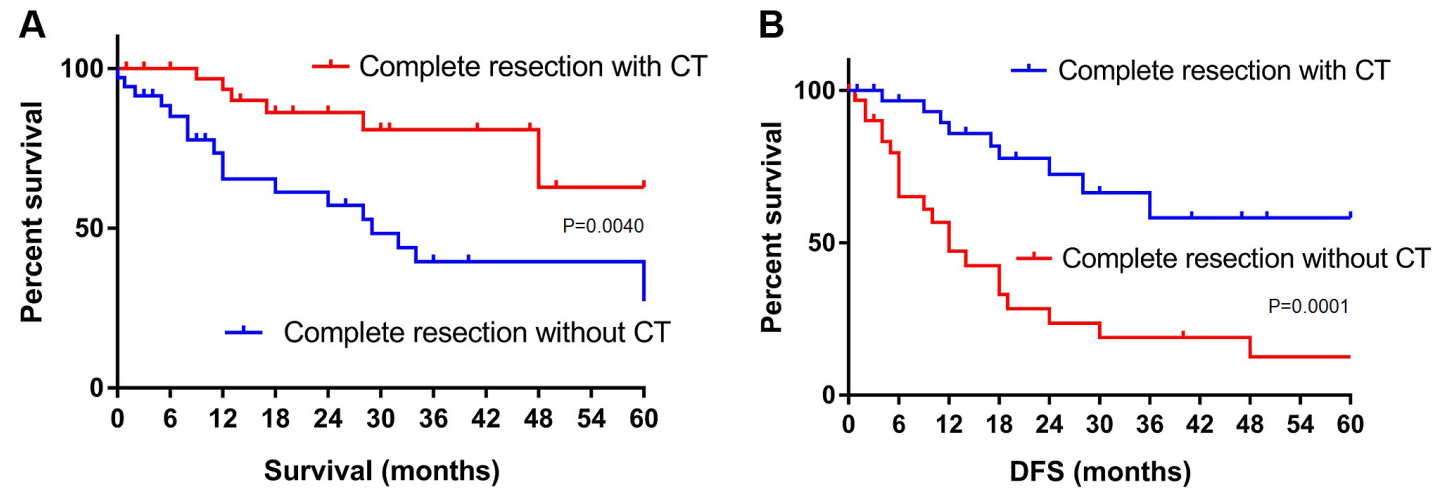

Figure 3. Kaplan-Meyer survival curves of patients with undifferentiated embryonal sarcoma of the liver. (A) Overall survival with and without chemotherapy. (B) DFS with and without chemotherapy. DFS, disease-free survival.

In the recent two decades, an increasing number of long-term survivors have been reported. These cases have mainly included children who underwent surgical tumor resection, especially with postoperative chemotherapy (39-42). In a review of 68 adult patients between 1995 and 2007, Lenze et al (5) observed a median survival of 29 months among all patients, and that patients who underwent complete tumor resection followed by adjuvant chemotherapy exhibited significantly improved survival compared with that of patients who underwent surgery alone. Similarly, the present results demonstrated significantly improved survival among patients treated with complete tumor resection plus adjuvant and/or neoadjuvant chemotherapy compared with patients treated with surgery alone. In addition, in pediatric cases, neoadjuvant chemotherapy can reduce the tumor size and stage, making complete surgical resection possible $(25,42,43)$. However, due to insufficient data, the effect of neoadjuvant chemotherapy in adult patients with UESL and its influence on survival cannot be currently assessed.

The present findings were limited by the retrospective study design and the low number of cases. The rarity of UESL, especially in adults, precludes large prospective single-institution studies. In addition, the effects of neoadjuvant treatment of UESL could not be evaluated in this study due to the limited relevant data in adult patients. However, this may be confirmed as a useful method in the future, based on the results of studies on pediatric UESL.
In conclusion, the present study reports one of largest case series of adult UESL to date. The results of our systematic literature review were the first to report the survival rates, which confirmed significantly improved survival following treatment with complete tumor resection plus chemotherapy compared with radical tumor resection alone. In the future, multi-institutional or global collaborative studies may represent the best approach to investigating adult UESL and standardizing its treatment.

\section{Acknowledgements}

Not applicable.

\section{Funding}

No funding was received.

\section{Availability of data and materials}

The datasets used and/or analyzed during the current study are available from the corresponding author on reasonable request.

\section{Authors' contributions}

BS and LG conceived and designed the study. BS, XH and SY performed the bioinformatics analysis and wrote the initial manuscript. LC, ZY and LG were involved in the conception 
of the study and edited the manuscript. All authors read and approved the final manuscript.

\section{Ethics approval and consent to participate}

The present study was approved by the Ethics Committee of the Beijing Tsinghua Changgung Hospital, and written informed consent was obtained from all patients.

\section{Patient consent for publication}

Not applicable.

\section{Competing interests}

The authors declare that they have no competing interests.

\section{References}

1. Liver Cancer Study Group of Japan: Primary liver cancer in Japan. Clinicopathologic features and results of surgical treatment. Ann Surg 211: 277-287, 1990.

2. Donovan EJ and Santulli TV: Resection of the left lobe of the liver for mesenchymoma: Report of case. Ann Surg 124: 90-93, 1946.

3. Stout AP: Mesenchymoma, the mixed tumor of mesenchymal derivatives. Ann Surg 127: 278-290, 1948.

4. Stocker JT and Ishak KG: Undifferentiated (embryonal) sarcoma of the liver: Report of 31 cases. Cancer 42: 336-348, 1978.

5. Lenze F, Birkfellner T, Lenz P, Hussein K, Länger F, Kreipe H and Domschke W: Undifferentiated embryonal sarcoma of the liver in adults. Cancer 112: 2274-2282, 2008.

6. Pachera S, Nishio H, Takahashi Y, Yokoyama Y, Oda K, Ebata T, Igami T and Nagino M: Undifferentiated embryonal sarcoma of the liver: Case report and literature survey. J Hepatobiliary Pancreat Surg 15: 536-544, 2008.

7. Chen JH, Lee $\mathrm{CH}$, Wei CK, Chang SM and Yin WY: Undifferentiated embryonal sarcoma of the liver with focal osteoid picture-a case report. Asian J Surg 36: 174-178, 2013.

8. Gerson G, Valença JT, Cavalcante JM and Coêlho RAB: Undifferentiated embryonal sarcoma of the liver in elderly: Case report and review of the literature. Indian J Pathol Microbiol 62: 129-131, 2019.

9. Capozza MA, Ruggiero A, Maurizi P, Mastrangelo S, Attinà G, Triarico S, Vellone M and Giuliante F: Undifferentiated embryonal sarcoma of the liver (UESL) in adolescents: An unexpected diagnosis. J Pediatr Hematol Oncol 41: e132-e134, 2019.

10. Esteban SG, Emilio CU, Emmanuel AF, Oscar SJ, Paulina CE and Angel MM: Undifferentiated embryonal sarcoma of the liver in adult patient: A report of two cases. Ann Hepatobiliary Pancreat Surg 22: 269-273, 2018.

11. Pandit N, Jaiswal LS, Shrestha V, Awale L and Adhikary S: Undifferentiated embryonal sarcoma of liver in an adult with spontaneous rupture and tumour thrombus in the right atrium. ANZ J Surg 89: E396-E397, 2019.

12. Pandit N, Deo KB, Jaiswal LS, Pradhan A and Adhikary S: Hanging undifferentiated embryonal sarcoma of the liver in adult: An unusual presentation of an aggressive tumor. J Gastrointest Cancer 50: 689-692, 2019.

13. Pinamonti M, Vittone F, Ghiglione F, Borasi A, Silvestri S and Coverlizza S: Unexpected liver embryonal sarcoma in the adult: Diagnosis and treatment. Case Rep Surg 2018: 8362012, 2018.

14. Beksac K, Mammadov R, Ciftci T, Guner G, Akyol A and Kaynaroglu V: Undifferentiated embryonal sarcoma of the liver in an adult patient. Cureus 10: e3037, 2018

15. Khan ZH, Ilyas K, Khan HH, Ghazanfar H, Hussain Q, Inayat F, Yasir $\mathrm{M}$ and Asim R: Unresectable undifferentiated embryonal sarcoma of the liver in an adult male treated with chemotherapy and orthotopic liver transplantation. Cureus 9: e1759, 2017.

16. Mori A, Fukase K, Masuda K, Sakata N, Mizuma M, Ohtsuka H, Morikawa T, Nakagawa K, Hayashi H, Motoi F, et al: A case of adult undifferentiated embryonal sarcoma of the liver successfully treated with right trisectionectomy: A case report. Surg Case Rep 3: 19, 2017.
17. Lee $\mathrm{KH}$, Maratovich $\mathrm{MN}$ and Lee KB: Undifferentiated embryonal sarcoma of the liver in an adult patient. Clin Mol Hepatol 22: 292-295, 2016.

18. Giakoustidis DE, Gargavanis AA, Katsiki ED, Salveridis NT, Antoniadis NA and Papanikolaou V: Undifferentiated embryonal sarcoma of the liver in a young female: Treatment with portal vein embolization and liver trisectonectomy. Korean J Hepatobiliary Pancreat Surg 20: 144-147, 2016.

19. Treitl D, Roudenko A, El Hussein S, Rizer M and Bao P: Adult embryonal sarcoma of the liver: Management of a massive liver tumor. Case Rep Surg 2016: 5625762, 2016.

20. Zanwar S, Goel M, Patkar S, Ramaswamy A, Shetty N, Ramadwar $M$ and Ostwal V: A case of ruptured adult embryonal sarcoma of the liver with excellent outcome after neoadjuvant chemotherapy. J Gastrointest Cancer 48: 100-102, 2017.

21. Masuda T, Beppu T, Doi K, Miyata T, Nakagawa S, Okabe H, Hayashi H, Ishiko T, Iyama K and Baba H: Repeated hepatic resections and radio-frequency ablations may improve the survival of adult undifferentiated embryonal sarcoma of the liver: Report of two cases. Surg Case Rep 1: 55, 2015.

22. Kallam A, Krishnamurthy J, Kozel J and Shonka N: Undifferentiated embryonal sarcoma of liver. Rare Tumors 7: 6009, 2015.

23. Xie ZY, Li LP, Wu WJ, Sun DY, Zhou MH and Zhao YG: Undifferentiated embryonal sarcoma of the liver mistaken for hepatic abscess in an adult. Oncol Lett 8: 1184-1186, 2014.

24. Cao Q, Ye Z, Chen S, Liu N, Li S and Liu F: Undifferentiated embryonal sarcoma of liver: A multi-institutional experience with 9 cases. Int J Clin Exp Pathol 7: 8647-8656, 2014.

25. Hanafiah M, Yahya A, Zuhdi Z and Yaacob Y: A case of an undifferentiated embryonal sarcoma of the liver mimicking a liver abscess. Sultan Qaboos Univ Med J 14: e578-e581, 2014.

26. Hong WJ, Kang YN and Kang KJ: Undifferentiated embryonal sarcoma in adult liver. Korean J Pathol 48: 311-314, 2014.

27. Ismail H, Dembowska-Bagińska B, Broniszczak D, Kaliciński P, Maruszewski P, Kluge P, Swięszkowska E, Kościesza A, Lembas A and Perek D: Treatment of undifferentiated embryonal sarcoma of the liver in children-single center experience. J Pediatr Surg 48: 2202-2206, 2013.

28. Jia C, Zhao W, Dai C, Wang X, Bu X, Peng S, Xu F, Xu Y and Zhao Y: Undifferentiated embryonal sarcoma of the liver in a middle-aged adult with systemic lupus erythematosus. World J Surg Oncol 11: 244, 2013.

29. Hu X, Chen H, Jin M, Wang X, Lee J, Xu W, Zhang R, Li S and Niu J: Molecular cytogenetic characterization of undifferentiated embryonal sarcoma of the liver: A case report and literature review. Mol Cytogenet 5: 26, 2012.

30. Varol U, Karaca B, Muslu U, Doğanay L, Değirmenci M, Uslu R and Göker E: Undifferentiated embryonal sarcoma of the liver in an adult patient: Case report. Turk J Gastroenterol 23: 279-283, 2012.

31. Dhanasekaran R, Hemming A, Salazar E and Cabrera R: Rare case of adult undifferentiated (embryonal) sarcoma of the liver treated with liver transplantation: Excellent long-term survival. Case Reports Hepatol 2012: 519741, 2012.

32. Lightfoot $\mathrm{N}$ and Nikfarjam M: Embryonal sarcoma of the liver in an adult patient. Case Rep Surg 2012: 382723, 2012.

33. Noguchi K, Yokoo H, Nakanishi K, Kakisaka T, Tsuruga Y, Kamachi H, Matsushita $M$ and Kamiyama T: A long-term survival case of adult undifferentiated embryonal sarcoma of liver. World J Surg Oncol 10: 65, 2012.

34. Tanaka S, Takasawa A, Fukasawa Y, Hasegawa T and Sawada N: An undifferentiated embryonal sarcoma of the liver containing adipophilin-positive vesicles in an adult with massive sinusoidal invasion. Int J Clin Exp Pathol 5: 824-829, 2012.

35. Tucker SM, Cooper K, Brownschidle S and Wilcox R: Embryonal (undifferentiated) sarcoma of the liver with peripheral angiosarcoma differentiation arising in a mesenchymal hamartoma in an adult patient. Int J Surg Pathol 20: 297-300, 2012.

36. Kim HH, Kim JC, Park EK, Hur YH, Koh YS, Cho CK, Kim HS and Kim HJ: Undifferentiated embryonal sarcoma of the liver presenting as a hemorrhagic cystic tumor in an adult. Hepatobiliary Pancreat Dis Int 10: 657-660, 2011.

37. Li XW, Gong SJ, Song WH, Zhu JJ, Pan CH, Wu MC and Xu AM: Undifferentiated liver embryonal sarcoma in adults: A report of four cases and literature review. World J Gastroenterol 16: 4725-4732, 2010. 
38. Leuschner I, Schmidt D and Harms D: Undifferentiated sarcoma of the liver in childhood: Morphology, flow cytometry, and literature review. Hum Pathol 21: 68-76, 1990.

39. Walker NI, Horn MJ, Strong RW, Lynch SV, Cohen J, Ong TH and Harris OD: Undifferentiated (embryonal) sarcoma of the liver. Pathologic findings and long-term survival after complete surgical resection. Cancer 69: 52-59, 1992.

40. Urban CE, Mache CJ, Schwinger W, Pakisch B, Ranner G, Riccabona M, Schimpl G, Brandesky G, Messner H,Pobegen W, et al: Undifferentiated (embryonal) sarcoma of the liver in childhood. Successful combined-modality therapy in four patients. Cancer 72: 2511-2516, 1993.

41. Weitz J, Klimstra DS, Cymes K, Jarnagin WR, D'Angelica M, La Quaglia MP, Fong Y, Brennan MF, Blumgart LH and Dematteo RP: Management of primary liver sarcomas. Cancer 109: 1391-1396, 2007.
42. Bisogno G, Pilz T, Perilongo G, Ferrari A, Harms D, Ninfo V, Treuner $\mathrm{J}$ and Carli M: Undifferentiated sarcoma of the liver in childhood: A curable disease. Cancer 94: 252-257, 2002.

43. Kim DY, Kim KH, Jung SE, Lee SC, Park KW and Kim WK: Undifferentiated (embryonal) sarcoma of the liver: Combination treatment by surgery and chemotherapy. J Pediatr Surg 37: $1419-1423,2002$

This work is licensed under a Creative Commons Attribution-NonCommercial-NoDerivatives 4.0 International (CC BY-NC-ND 4.0) License. 